\title{
Omentin as a novel biomarker of metabolic risk factors
}

\author{
Rei Shibata ${ }^{1}$, Noriyuki Ouchi ${ }^{2 *}$, Ryotaro Takahashi ${ }^{3}$, Yuya Terakura ${ }^{1}$, Koji Ohashi $^{2}$, Nobuo Ikeda ${ }^{3}$, Akiko Higuchi ${ }^{4}$, \\ Hiroko Terasaki ${ }^{5}$, Shinji Kihara ${ }^{5}$ and Toyoaki Murohara ${ }^{1}$
}

\begin{abstract}
Background: Omentin is an adipocytokine that is abundantly expressed in visceral fat tissue. We investigated the association of omentin with the number of metabolic risk factors.

Finding: The study population comprised 201 Japanese men who underwent annual health checkups. Plasma omentin levels were determined by enzyme-linked immunosorbent assay. We divided the subjects into 4 groups according to omentin levels. A reduction of plasma omentin levels significantly correlated with an increase in the mean number of metabolic risk factors such as increased waist circumference, dyslipidemia, high blood pressure and glucose intolerance.
\end{abstract}

Conclusions: Circulating omentin levels negatively correlated with the multiplicity of metabolic risk factors, suggesting that omentin acts as a biomarker of metabolic disorders.

Keywords: Omentin, Adipocytokine, Metabolic disorders, Risk factors, Biomarkers

\section{Findings}

Obesity has become a major health problem in industrial countries with increasing prevalence in adults and children [1]. Obesity, in particular, excess of visceral adipose tissue, is causally linked with a cluster of metabolic disorders including glucose intolerance, dyslipidemia, and hypertension, also known as metabolic syndrome [2-4].

Accumulating evidence indicates that adipose tissue is an active endocrine organ that produces various bioactive substances, also known as adipocytokines or adipokines $[4,5]$. Excess adipose mass observed in obese individuals is linked with increased production of many adipocytokines including tumor necrosis factor- $\alpha$ and interleukin-6, which potentially promotes metabolic dysfunction $[5,6]$. Fat tissues also produce a smaller number of adipocytokines including adiponectin and Sfrp5, which are beneficial in the setting of obesity-linked complications $[5,7,8]$. The imbalance of production of these adipocytokines may cause the development of obesityrelated metabolic and vascular disorders.

\footnotetext{
* Correspondence: nouchi@med.nagoya-.ac.jp

${ }^{2}$ Department of Molecular Cardiology, Nagoya University Graduate School of Medicine, 65 Tsurumai, Showa-Ku, Nagoya466-8550Japan

Full list of author information is available at the end of the article
}

Omentin/intelectin-1 is an adipocytokine that exists in human blood stream [9-11]. While omentin is highly expressed in human visceral fat tissue, circulating omentin levels are reduced in obese subjects [12]. Omentin is also down-regulated in association with obesity-linked metabolic disorders including insulin resistance, glucose intolerance and type 2 diabetes [12-14]. However, nothing is known about the relationship between omentin and metabolic risk factors. Here, we examined whether circulating omentin levels associate with the multiplicity of metabolic risk factors.

This study included 201 Japanese men who visited Chunichi Hospital in Nagoya for an annual health checkup. All subjects had no history of cardiovascular disease and took no medication. All subjects enrolled in this study provided written informed consent. This study was approved by the ethics committee of the Nagoya University School of Medicine and the Chunichi Hospital.

We assessed the presence or absence of four metabolic risk factors: increased waist circumference, dyslipidemia, elevated blood pressure (BP), and dysglycemia/impaired glucose tolerance. An increase in waist circumference was defined as $\geq 85 \mathrm{~cm}$. Dyslipidemia represented elevated triglycerides $(>150 \mathrm{mg} / \mathrm{dl})$ and/or low HDL cholesterol $(<40 \mathrm{mg} / \mathrm{dl})$. Elevated BP was defined as systolic BP of $\geq$ 


\section{Table 1 Clinical characteristics}

\begin{tabular}{ll}
\hline Parameters & Subjects $(\mathbf{n}=\mathbf{2 0 1})$ \\
\hline Age $($ years $)$ & $53.9 \pm 9.0$ \\
BMl $\left(\mathrm{kg} / \mathrm{m}^{2}\right)$ & $23.3 \pm 2.6$ \\
Waist circumference $(\mathrm{cm})$ & $84.7 \pm 6.8$ \\
Systolic BP $(\mathrm{mmHg})$ & $116.6 \pm 17.6$ \\
Diastolic BP $(\mathrm{mmHg})$ & $72.9 \pm 12.1$ \\
Fasting glucose $(\mathrm{mg} / \mathrm{dl})$ & $103.6 \pm 12.4$ \\
Hemoglobin A1c $(\%)$ & $5.06 \pm 0.53$ \\
Fasting insulin $(\mu \mathrm{l} / \mathrm{ml})$ & $5.82 \pm 3.8$ \\
Total cholesterol $(\mathrm{mg} / \mathrm{dl})$ & $204.0 \pm 34.8$ \\
LDL cholesterol $(\mathrm{mg} / \mathrm{dl})$ & $110.7 \pm 25.8$ \\
HDL cholesterol $(\mathrm{mg} / \mathrm{dl})$ & $55.3 \pm 13.8$ \\
Triglyceride $(\mathrm{mg} / \mathrm{dl})$ & $137.2 \pm 75.6$ \\
Creatinine $(\mathrm{mg} / \mathrm{dl})$ & $0.87 \pm 0.13$ \\
Log hsCRP $(\mathrm{mg} / \mathrm{dl})$ & $2.63 \pm 0.44$ \\
Log omentin $(\mathrm{ng} / \mathrm{ml})$ & $2.66 \pm 0.01$ \\
\hline
\end{tabular}

Data are presented as means \pm S.E

$130 \mathrm{mmHg}$ or diastolic $\mathrm{BP}$ of $\geq 85 \mathrm{mmHg}$ on repeated measurements. After an appropriate rest of 10minutes, sitting BP was measured. Dysglycemia/impaired glucose tolerance represented hyperglycemia (fasting glucose level of $\geq 110 \mathrm{mg} / \mathrm{dl}$ ).

Venous blood samples were obtained for chemical analysis after an overnight fast. Plasma omentin levels were determined with omentin enzyme-linked immunosorbent assay (ELISA) kit (Bio Vendor, NC, USA). Heparin was used for plasma sampling for measurement of omentin. The intra-assay and interassay coefficients of variation of this kit were $4.1 \%$ and $4.8 \%$, respectively. Standard assays were used to measure glucose, hemoglobin A1c, insulin, total cholesterol, HDL cholesterol, LDL cholesterol, triglycerides, creatinine and high-sensitive C-reactive protein (hsCRP) levels.

Summary statistics are presented as mean \pm standard error (S.E.) for continuous variables. Non-parametric Kruskal-Wallis analysis of variance test and multiple logistic regression analyses were used to analyze the relationship between the number of metabolic risk factors and omentin levels. A value of $\mathrm{p}<0.05$ was considered significant. All analyses were performed using JMP (version 6.03; SAS Institute Inc).

The study population compromised 201 Japanese men who underwent annual health checkups. Clinical characteristics are shown in Table 1. Mean values of BMI (body mass index), waist circumference, blood pressure, hemoglobin A1c, total cholesterol, LDL cholesterol, HDL cholesterol, triglyceride, and creatinine were within the normal range. Because the distributions of omentin were skewed, we used logarithmically transformed values for statistical analysis. The distributions of log-omentin levels have been confirmed to fit the normal distribution by Shapiro-Wilk tests $(\mathrm{p}<0.01)$. Mean plasma log-omentin level was $2.66 \pm 0.01 \mathrm{ng} / \mathrm{ml}$.

We categorized the subjects into 4 groups according to plasma omentin levels as follows: category $1,<2.59 \mathrm{ng} / \mathrm{ml}$; category $2, \geq 2.59 \mathrm{ng} / \mathrm{ml},<2.66 \mathrm{ng} / \mathrm{ml}$; category $3, \geq 2.66$ $\mathrm{ng} / \mathrm{ml},<2.72 \mathrm{ng} / \mathrm{ml}$; and category $4, \geq 2.72 \mathrm{ng} / \mathrm{ml}$. The number of subjects in the 4 categories were 50,51, 49 and 51 , respectively. The average number of metabolic risk factors significantly increased with the decline in the quartiles of plasma omentin levels (category 1: $1.58 \pm 0.18$; category 2: $1.40 \pm 0.16$; category 3 : $0.98 \pm 0.15$; category 4 : $0.78 \pm 0.12)(\mathrm{P}<0.001)$ (Figure 1A). Omentin levels were also significantly lower in subjects with one or more risk factors than in those without risk factors $(\mathrm{P}=0.001)$ (Figure 1B). Multiple logistic regression analyses after adjusting for age revealed that omentin levels were
A

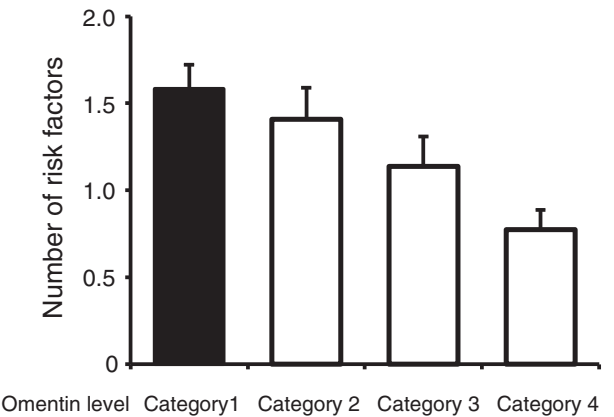

B

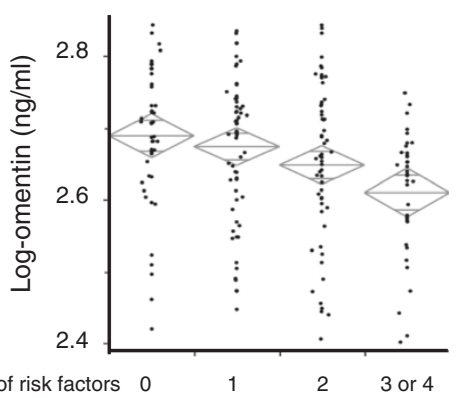

Figure 1 Association between plasma omentin levels and number of metabolic risk factors. Plasma omentin concentrations were determined by an ELISA kit. (A) Subjects were divided into 4 categories according to plasma log omentin concentration as follows: category 1 , $<2.59 \mathrm{ng} / \mathrm{ml}$; category $2, \geq 2.59 \mathrm{ng} / \mathrm{ml},<2.66 \mathrm{ng} / \mathrm{ml}$; category $3, \geq 2.66 \mathrm{ng} / \mathrm{ml},<2.72 \mathrm{ng} / \mathrm{ml}$; and category $4, \geq 2.72 \mathrm{ng} / \mathrm{ml}$. (B) Log-omentin levels were divided into 4 categories according to $0,1,2,3$ or 4 metabolic risk factors. 


\begin{tabular}{|c|c|c|}
\hline No. of metabolic risks & OR $(95 \% \mathrm{Cl})$ & $P$ value \\
\hline$\overline{0^{*}}$ & $1.00(-)$ & - \\
\hline 1 & $0.488(-0.005,0.003)$ & 0.536 \\
\hline 2 & $0.091(-0.008,-0.004)$ & 0.033 \\
\hline $3-4$ & $0.017(-0.013,-0.004)$ & $P<0.001$ \\
\hline
\end{tabular}

Multiple logistic regression analyses include age and omentin

*Standard category. OR; odds ratio, Cl: confidence intervals

associated with a significant decrease in the number of metabolic risk factors (Table 2).

In the present study, we, for the first time, demonstrate that circulating levels of omentin inversely correlate with the number of metabolic risk factors. Individuals with excess of visceral fat accumulation have a high risk of the development of metabolic syndrome [3]. Among various human tissues, visceral adipose tissue produces a large amount of omentin, and its gene expression in visceral fat depot is reduced in obese subjects [12]. Low levels of circulating omentin are associated with obesity-induced metabolic dysfunction such as insulin resistance and glucose intolerance $[12,13]$. These observations suggest that reduced levels of omentin may be an indicator of visceral fat accumulation, thereby correlating with the clustering of metabolic disorders.

Plasma concentration of omentin is associated with endothelium-dependent vasodilation [15]. Circulating omentin levels are negatively correlated with carotid intima-media thickness, which is a marker of early atherosclerosis [16]. Low levels of circulating omentin are also associated with the prevalence of coronary artery disease $[17,18]$. These data suggest that omentin may represent a biomarker for not only metabolic disorders, but also cardiovascular diseases.

The role of omentin in regulating metabolic function is poorly defined. A previous study showed that omentin stimulates glucose uptake in response to insulin in cultured adipocytes [9], suggesting that omentin exerts beneficial actions on insulin sensitivity. Future experimental researches are required to clarify the functional significance of omentin in the context of metabolic diseases.

In conclusion, the present study indicates that lower concentration of circulating omentin is linked with an increase in multiplicity of metabolic risk factors, suggesting that omentin serves as a biomarker for assessment of metabolic risk factors.

\section{Abbreviations \\ BMI: body mass index; BP: blood pressure; ELISA: enzyme-linked immunosorbent assay; hsCRP: high-sensitive C-reactive protein.}

\section{Competing interests}

The authors declare that they have no competing interests
Author contributions

R.S., N.O., R.T., K.O., and T.M. designed and carried out the studies. N.I., A.H., T. Y., H. T., and S.K. analyzed the data. N.O. and R.S. wrote the paper. All authors read and approved the final manuscript.

\section{Acknowledgments}

This study was funded by Grant-in-Aid for Scientific Research, and grants from Suzuken Memorial Foundation, Japan Research Foundation for Clinical Pharmacology and the Uehara Memorial Foundation to N. Ouchi. R. Shibata was supported with the Grant-in-Aid for Young Scientists B, the Uehara Memorial Foundation, Japan Heart Foundation/Novartis Grant for Research Award on Molecular and Cellular Cardiology, 2011 and Japan Heart Foundation \& Astellas/Pfizer Grant for Research on Atherosclerosis Update.

\section{Author details}

${ }^{1}$ Department of Cardiology, Nagoya University Graduate School of Medicine, Nagoya, Japan. ${ }^{2}$ Department of Molecular Cardiology, Nagoya University Graduate School of Medicine, 65 Tsurumai, Showa-Ku, Nagoya466-8550Japan. ${ }^{3}$ Department of Cardiology, Chunichi Hospital, NagoyaJapan. ${ }^{4}$ Department of Ophthalmology, Nagoya University Graduate School of Medicine, Nagoya, Japan. ${ }^{5}$ Department of Biomedical Informatics, Osaka University Graduate School of Medicine, Nagoya, Japan.

Received: 28 March 2012 Accepted: 26 July 2012

Published: 26 July 2012

\section{References}

1. Flegal KM, Carroll MD, Kuczmarski RJ, Johnson CL: Overweight and obesity in the united states: Prevalence and trends, 1960-1994. Int J Obes Relat Metab Disord. 1998, 22:39-47.

2. Nielsen S, Jensen MD: Obesity and cardiovascular disease: Is body structure a factor? Curr Opin Lipidol 1997, 8:200-204.

3. Despres JP, Lemieux I: Abdominal obesity and metabolic syndrome. Nature 2006, 444:881-887.

4. Matsuzawa Y: Therapy insight: Adipocytokines in metabolic syndrome and related cardiovascular disease. Nat Clin Pract Cardiovasc Med. 2006, 3:35-42.

5. Ouchi N, Parker JL, Lugus JJ, Walsh K: Adipokines in inflammation and metabolic disease. Nat Rev Immunol 2011, 11:85-97.

6. Ouchi N, Kihara S, Funahashi T, Matsuzawa Y, Walsh K: Obesity, adiponectin and vascular inflammatory disease. Curr Opin Lipidol 2003, 14:561-566.

7. Shibata R, Ouchi N, Murohara T: Adiponectin and cardiovascular disease. Circ J 2009, 73:608-614.

8. Walsh K: Adipokines, myokines and cardiovascular disease. Circ J 2009, 73:13-18.

9. Yang RZ, Lee MJ, Hu H, Pray J, Wu HB, Hansen BC, Shuldiner AR, Fried SK, McLenithan JC, Gong DW: Identification of omentin as a novel depotspecific adipokine in human adipose tissue: Possible role in modulating insulin action. Am J Physiol Endocrinol Metab 2006, 290:E1253-E1261.

10. Schaffler A, Neumeier M, Herfarth H, Furst A, Scholmerich J, Buchler C: Genomic structure of human omentin, a new adipocytokine expressed in omental adipose tissue. Biochim Biophys Acta 2005, 1732:96-102.

11. Tsuji S, Uehori J, Matsumoto M, Suzuki Y, Matsuhisa A, Toyoshima K, Seya T: Human intelectin is a novel soluble lectin that recognizes galactofuranose in carbohydrate chains of bacterial cell wall. J Biol Chem 2001, 276:23456-23463.

12. de Souza Batista CM, Yang RZ, Lee MJ, Glynn NM, Yu DZ, Pray J, Ndubuizu K, Patil S, Schwartz A, Kligman M, Fried SK, Gong DW, Shuldiner AR, Pollin TI, McLenithan JC: Omentin plasma levels and gene expression are decreased in obesity. Diabetes 2007, 56:1655-1661.

13. Pan HY, Guo L, Li Q: Changes of serum omentin-1 levels in normal subjects and in patients with impaired glucose regulation and with newly diagnosed and untreated type 2 diabetes. Diabetes Res Clin Pract. 2010, 88:29-33.

14. Tan BK, Adya R, Farhatullah S, Lewandowski KC, O'Hare P, Lehnert H, Randeva HS: Omentin-1, a novel adipokine, is decreased in overweight insulin-resistant women with polycystic ovary syndrome: Ex vivo and in vivo regulation of omentin-1 by insulin and glucose. Diabetes 2008, 57:801-808 
15. Yamawaki H, Tsubaki N, Mukohda M, Okada M, Hara Y: Omentin, a novel adipokine, induces vasodilation in rat isolated blood vessels. Biochem Biophys Res Commun 2010, 393:668-672.

16. Shibata R, Takahashi R, Kataoka Y, Ohashi K, Ikeda N, Kihara S, Murohara T, Ouchi N: Association of a fat-derived plasma protein omentin with carotid artery intima-media thickness in apparently healthy men. Hypertens Res 2011, 34:1309-1312.

17. Zhong X, Zhang HY, Tan H, Zhou Y, Liu FL, Chen FQ, Shang DY: Association of serum omentin-1 levels with coronary artery disease. Acta Pharmacol Sin. 2011, 32:873-878.

18. Shibata R, Ouchi N, Kikuchi R, Takahashi R, Takeshita K, Kataoka Y, Ohashi K, Ikeda N, Kihara S, Murohara T: Circulating omentin is associated, with coronary artery disease in men. Atherosclerosis 2011, 219(2):811-4.

doi:10.1186/1758-5996-4-37

Cite this article as: Shibata et al:: Omentin as a novel biomarker of metabolic

risk factors. Diabetology \& Metabolic Syndrome 2012 4:37.

\section{Submit your next manuscript to BioMed Central and take full advantage of:}

- Convenient online submission

- Thorough peer review

- No space constraints or color figure charges

- Immediate publication on acceptance

- Inclusion in PubMed, CAS, Scopus and Google Scholar

- Research which is freely available for redistribution 